\title{
Topology-directed Design of Porous Organic Frameworks and Their Advanced Applications
}

\author{
Xiaoqin Zou ${ }^{\mathrm{a}}$, Hao Ren ${ }^{\mathrm{a}}$ and Guangshan $\mathrm{Zhu}^{\mathrm{ab} *}$ \\ Received (in $X X X, X X X)$ Xth $X X X X X X X X X 20 X X$, Accepted Xth $X X X X X X X X X 20 X X$ \\ DOI: $10.1039 / b 000000 x$
}

Porous organic frameworks (POFs) as an important subclass of nanoporous materials are of great interests in materials science. In recent years, the discovery and creation of POFs with excellent properties for advanced applications has attracted much attention; and intensive efforts have been contributed to this field. As a result, the design of materials with multi-functionalities is an ever-pursuit dream of materials scientists and engineers. In this respect, a new concept based on topology chemistry is introduced for the rational and target synthesis of POF materials. The present feature article provides an overview on the relationship of building blocks or starting monomers, underlying topological nets, and pre-determined structures. Several important nets are included successively from one to three dimensions. In addition, special emphasis is given to the advanced applications of designed POF materials in the current paper.

\section{Introduction}

Nanoporous materials are consisting of a regular inorganic or organic structure, supporting a periodic and porous system. Their pore sizes fall into the nanoscale region of $0.2 \mathrm{~nm}$ to $50 \mathrm{~nm}$. Nanoporous solids as a subclass of nanomaterials have been an ever-growing interdisciplinary field of study attracting tremendous interests thanks to their nanostructures and versatile skeletons (ranging from inorganic, inorganic-organic and purely organic components). ${ }^{1}$ Between the nanoporous solids three individual classes can be recognized, such as zeolites, metalorganic frameworks (MOFs), and porous organic frameworks (POFs). Zeolites are crystalline aluminosilicates with frameworktype structures that form pores with uniform sizes of molecular dimensions by corner sharing $\mathrm{TO}_{4}$ tetrahedra (e.g. $\mathrm{SiO}_{4}$ and $\left.\mathrm{AlO}_{4}\right)^{2}$ Metal-Organic Frameworks (MOFs), also known as porous coordination polymers (PCPs), are crystalline compounds consisting of metal ions or clusters coordinated to often rigid organic molecules to form one-, two-, or three-dimensional structures that can be porous. ${ }^{3}$ Great achievements in the field of zeolite and MOF materials have been witnessed by a library of their diverse and aesthetically pleasing structures with a large pore size range (from 0.3 to $3 \mathrm{~nm}$ ); and the parallel exploitation of their important uses in various domains, such as adsorbents, storage/separation, catalysis, optical/magnetic devices, chemical sensors, and biological applications, which are benefitted from their specific properties (for instance, well-defined pores, high surface areas, unique surface property and adsorption affinity). Very recently, POFs (such as covalent organic frameworks (COFs), conjugated porous polymers (CPPs), or elemental organic frameworks (EOFs)), ${ }^{4-11}$ emerging as another family member of nanoporous materials, have been a hot and frontier research theme in materials science and technology; the topic of which is our focus in the present feature article. They are composed of different organic moieties linked by covalent bonds, resulted in ordered and rigid structure. This class of POF materials possesses highly permanent porosity, exceptionally high thermal stability (up to $600^{\circ} \mathrm{C}$ ), and low framework density. By scanning the synthetic routes and structures, two distinguished features of porosity and shared building blocks are well recognized in the constructed POF frameworks. Porosity is a very important physical characteristic of most POF materials, which determines the amount of void space inside the objected material. In the preparation of POFs, the pores are generated through the polymerization of monomers (e.g. homo or cross-coupling). The pores offer vast abilities for atoms, ions and molecules to be interacted or adsorbed on the interior surfaces in a nanometer sized space. The porous property of POF materials would open new routes in the areas of inclusion, host-guest, molecular manipulations and reaction chemistry. In addition to the aforementioned porosity, the building blocks make a great contribution to the construction of POF skeletons. Different types of organic monomers as struts and joints undergo the formation of various organic secondary building units (SBUs), which are further assembled into versatile architectures. The rich compositions of organic moieties, active sites on the internal pores and the connection geometry provide POF solids with functional applications such as adsorption, catalysis and sensing. ${ }^{12-14}$ POF solids can generally classified into crystalline with well-resolved lattice planes and non-crystalline (amorphous or non long-range ordered) materials. Very recently, well-ordered POFs (crystalline, semicrystalline) have attracting more and more interests thanks to their uniform pore system and simplicity in structure. To better understand the context of POF materials, the underlying topology would give us a clear overview on how the building blocks are connected/bridged with each other, and how 
regular pores/cavities are organized in an artistic way.

\section{Topology Concerns in POFs}

A topology is given as a set of ordered pairs of the vertices (points) on a graph (also described in terms of nets); each pair determined an edge of the graph. ${ }^{15}$ In chemistry, the graph vertices and edges correspond to atoms/molecules and interatomic/molecular bonds, respectively. Topology has found many applications in the modern condensed matter physics and chemistry, particularly in crystals. The reticular chemistry with the same concept of topology-based science has been commonly practiced in the synthesis of metal-organic frameworks wherein metal ions/clusters acted as vertices and coordination bonds served as edges to make porous coordination polymers, which is developed by the group of Yaghi. ${ }^{16}$ This chemistry can be extended to linking organic units by strong covalent bonds of small or light elements (for example, C-C, C-N, and B-O) to give a new class of highly robust and porous solids termed as COFs, the work of which is also pioneered by the same group. ${ }^{17}$ The underlying topology plays a fundamental role in bridging different kinds of building blocks and the possibly resulted structures, which is schematically presented in Fig. 1. Organic monomers are generally utilized in the construction of secondary building units (SBUs), which are the basic and necessary components in POFs (Fig. 1). Meanwhile, the connection manners (possible sites for forming bonds) direct the geometry of the dimensional nets (one-, two- and three-periodic nets) for the determination of complete topological representatives (stable and preferred ones) by some methods of simplification/transformation, which can be seen from the exemplified monomers in Fig. 1. Additionally, the "true" topology combined with SBUs and their connectivity, is important for predicting the most likely structure (Fig. 1). From topological point of view, a comprehensive understanding of the underlying topologies gives us useful hints in the directionality for the construction of POFs with open and robust frameworks. On the other hand, the preparations of POFs are performed by serendipity in the initial growing stage of discovering new materials.

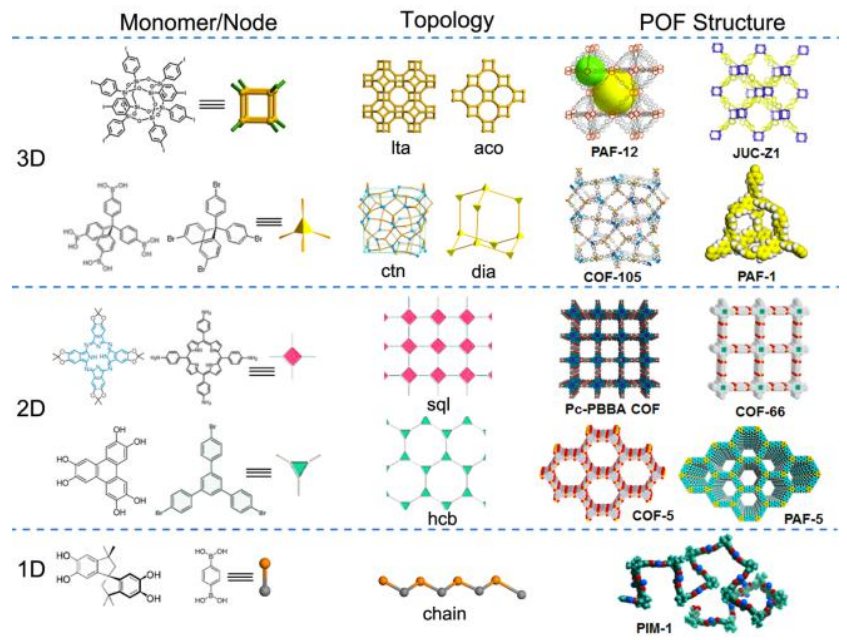

Fig. 1 Schematic illustration of building blocks, underlying topologies, and final structures for POF materials.

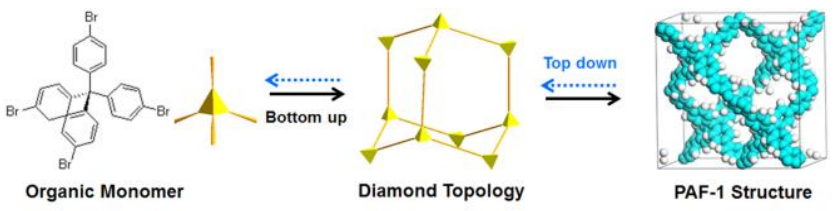

Fig. 2 Topology-directed synthesis of POF material (PAF-1) via bottom up and top-down approaches.

Instead of this trial-and-error way, a facile and rational strategy is greatly demanded for the design and synthesis of POF materials systematically. Based on this consideration, topology-directed approach can realize the feasibility of synthesizing predetermined POF structures with unprecedented freedom to design porous materials for specific purposes. ${ }^{16}$ Thus, our interests are focused on the synthesis of ordered POF materials (crystalline and some typical structure-ordered ones) starting from the concept of topological chemistry. An example of three-dimensional POFs with diamond topology is presented in Fig. 2 to show you how this approach works in either bottom-up or top-down bidirectional way. In the bottom-up way, the organic monomers are fixed. With a careful examination of available nodes, the preferred topology would be expected assisted with computer tools (e.g. material studio software (MS), TOPOS). In the same manner, once the objective POF structure is specifically targeted; the underlying topological possibilities can be produced by computing skills or databases (i.e. RCSR database). Subsequently, the ideal candidate monomers would be selected by high throughput screening in the top-down method. From this point of view, topology-based strategy offers a guideline for the fabrication of POF architectures with interesting structure properties aiming for diverse applications.

\section{Topology-based synthesis of POFs with potentially diversified applications}

\subsection{One-dimensional POFs}

Low-dimensional organic polymers particular for onedimensional synthetic ones, such as polyethylene, nylon, and polystyrene; have found wide applications in daily life. These 1D polymers are obtained via the covalent polymerization of small building units (e.g. alkenes, amines, and acids). With a close look at the configurations of the small units, it can be found that those 1D polymers are built up of linear monomers. Recently, an important development in the design of low-dimensional porous organic polymers has been witnessed, such as polymers of intrinsic microporosity (PIMs), some hyper-crosslinked polymers (HCPs) and conjugated microporous polymers (CMPs). The underlying topology of 1D POFs can be deemed as quasiregular chains, which is the origin for creating pores. As seen from the relationship between building blocks and topology, two-vertex organic monomers are commonly used to synthesize POF materials with $1 \mathrm{D}$ chain nets. Bearing this in mind, the group of McKeown and Budd first reported the preparation of polymer microporous networks (PIMs) from molecular scaffolds of biscatechol derivatives (Fig. 3a). ${ }^{18}$ The network polymer occurs via dibenzodioxane formation (Fig. 3b). This microporous polymer possesses an open structure, arising from the folding of fragments in the quasi chain (Fig. 3c). 


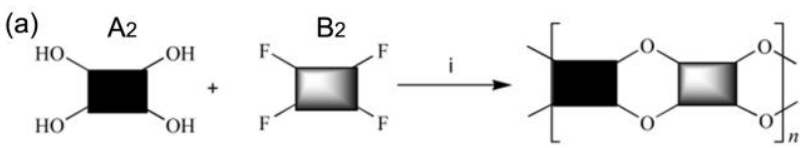

(b) possible $A_{2}$ units

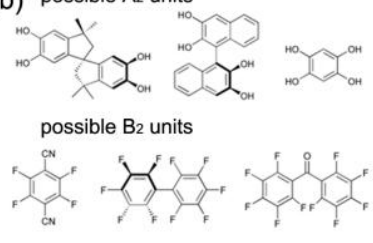

(c)



Fig. 3 (a) The synthetic pathway, (b) the initial organic monomers, and (c) model structure of PIMs. (Reproduced from ref. 18.).

This open structure offers the polymer with a significant proportion of micropores with dimensions in the range $0.4-0.8$ $\mathrm{nm}$, and with high intrinsic microporosity (the total pore volume of $0.78 \mathrm{~cm}^{3} \mathrm{~g}^{-1}$, and surface area above $\left.600 \mathrm{~m}^{2} \mathrm{~g}^{-1}\right)$. In the same manner, many PIMs have been produced with the appropriate aromatic tetrol monomers. ${ }^{19}$ More recently, Thomas etc. described the synthesis of a new type of microporous rigid polymers with ladder structures (a subclass of $1 \mathrm{D}$ chain). The ladder-type aromatic networks with high BET surface areas of up to $1650 \mathrm{~m}^{2} \mathrm{~g}^{-1}$ are obtained by a cyclotrimerization reaction. ${ }^{20}$ Up to date, there are some but not many reports on the synthesis of quasichain-like POFs (such as PIMs, CMPs and HCPs) with the potential applications in gas adsorption and separation. ${ }^{21-26}$

\subsection{Two-dimensional POFs}

The design and synthesis of crystalline extended porous organic frameworks in which the building blocks are linked by strong covalent bonds, is a developing research area; the topic of which is our first focus in this feature article. 2D POFs organize molecular components into periodic layered networks through forming $\pi$-electron interaction systems. In order to achieve 2D POFs with defined topological structures, planar (linear, triangle or square) segments are needed. For clear clarity, the types of SBUs and corresponding structures, and their connectivity are displayed in Fig. 4. These materials exhibit many desirable properties, including well-ordered structures with uniform pores, high $\pi$-electron density, permanent porosity with high specific surface area, outstanding thermal stability, and the lowest densities of any organic materials. The first achievement in the reticular synthesis of crystalline 2D POF materials with regular pore size was made in the group of Yaghi in $2005 .{ }^{17}$ The strategy for synthesizing the first two COF members (COF-1 and COF-5) involves using one-step condensation reactions of discrete molecules known to produce six- and five-membered rings that can be appropriated for the synthesis of their extended analogs, as shown in Fig. 5. The synthesis of COF-1 is based on the molecular dehydration reaction (Fig. 5a), in which three boronic acid molecules converge to form a planar six-membered $\mathrm{B}_{3} \mathrm{O}_{3}$ (boroxine) ring with the elimination of three water molecules. Such molecular structures of cyclotrimerized boronic acids are held in planar conformations by hydrogen bonds. With this knowledge, this reaction was extended to 1,4-benzenediboronic acid (BDBA), in which a honeycomb-like (hcb) structure was expected to form upon dehydration as shown in Fig. 5b.

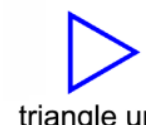

triangle unit
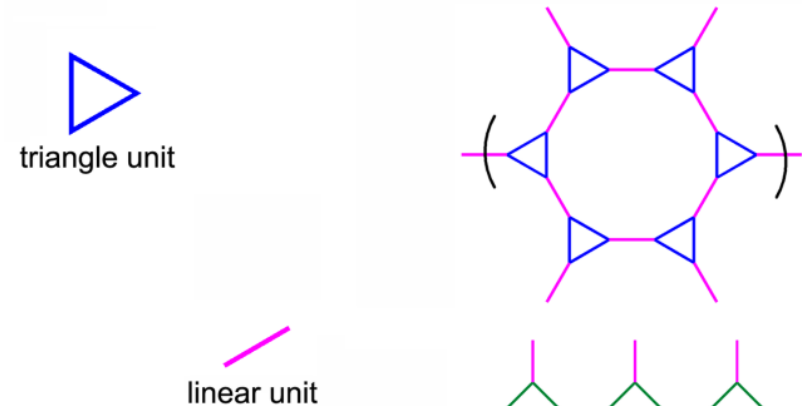

inear unit

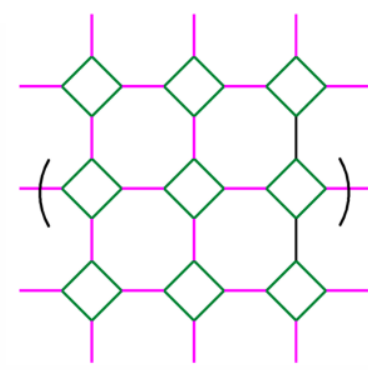

extended structures

Fig. 4 Planar building blocks and their corresponding structures.

(a)
3

boronic acid

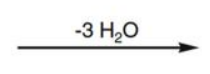

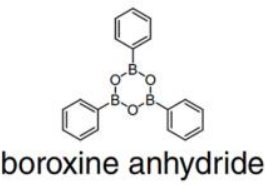

(b)

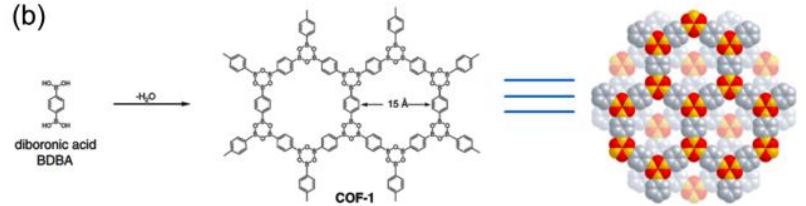

(c)

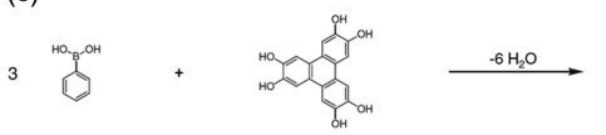

boronic acid hexahydroxy triphenylene HHTP

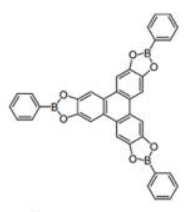

triboronate ester

(d)

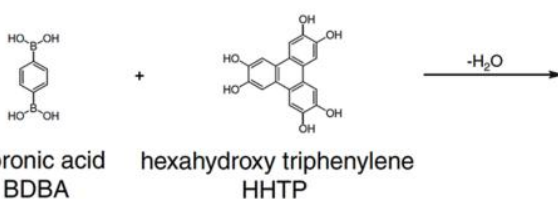

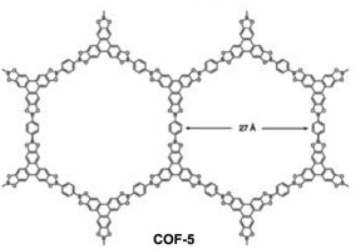
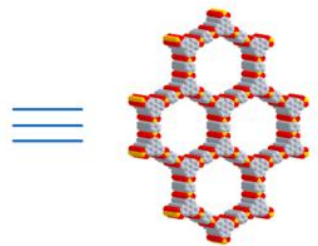

Fig. 5 Condensation reactions of boronic acids used to produce discrete molecules and extended COFs; and their simulated structures. (Reprinted with permission from ref. 17. Copyright 2005 AAAS.).

For COF-5, an analogous condensation reaction was used. The dehydration reaction between phenylboronic acid and 2,3,6,7,10,11-hexahydroxytriphenylene (HHTP), a trigonal building block, generates a five-membered $\mathrm{BO}_{2} \mathrm{C}_{2}$ ring (Fig. 5c). It is found that the entirely coplanar extended sheet structure shares the same hcb topology (Fig. 5d). The pore sizes of COF-1 
and COF-5 are determined to be $15 \AA$ and $27 \AA$ respectively, which are derived from $\mathrm{N}_{2}$ adsorption isotherms. These two porous architectures exhibit high thermal stability (up to $\left.500 \sim 600^{\circ} \mathrm{C}\right)$, permanent porosity, and high surface areas (711 and $1590 \mathrm{~m}^{2} \mathrm{~g}^{-1}$, respectively). Later on, the same group developed the general utility and applicability of reticular chemistry for the systematic design of composition, structure, and porosity of a series of hcb topology-based COFs having pore sizes ranging 9$32 \AA$ (i.e. COF-6, COF-8, COF-10). ${ }^{27-29}$ This strategy for producing porous architectures via forming $\mathrm{B}-\mathrm{O}$ bonds has been inherited by many scholars. ${ }^{30-36}$ To be mentioned, the synthesis of POF materials with large pores exceeding $4 \mathrm{~nm}$ has also been achieved by reversible condensation reaction in the groups of Bein and Dichtel. ${ }^{37-38}$ These POFs with pore size range from micro to meso scale have paved their ways in different application domains (details are listed in Table 1) of optoelectronic devices, ${ }^{39-40}$ and $\mathrm{CO}_{2}$ capture. ${ }^{41}$ For instance, the luminescence and semiconducting properties of COF consisting of pyrene and triphenylene functionalities alternately linked in a belt shape was investigated. ${ }^{39}$ The topologically designed COF with pore size of $3.2 \mathrm{~nm}$ exhibited a significantly depolarized fluorescence with an extremely low $p$ value (fluorescence anisotropy) of 0.017 . Further, the highly ordered structure enables the formation of a conductive path, which makes as-synthesized COF material promising as semiconductors with high electrical conductivity. The preparation of POFs featured in hcb topology can be also accomplished with other linear and triangle nodes via specific reactions. The library of starting monomers with various nodes for producing hcb-based POFs is summarized in Table 1. Instead of forming B-O bonds, linking molecular building blocks through $\mathrm{C}-\mathrm{N}$ covalent bonds is prone to yield 2D porous architectures. The representative example is evidenced by CTF$1{ }^{42}$ Simple aromatic nitriles are selected as the target organic monomers. Fig. 6a shows a schematic representation of the formation of a triazine-based framework material by a trimerization reaction of 1,4-dicyanobenzene. (a)

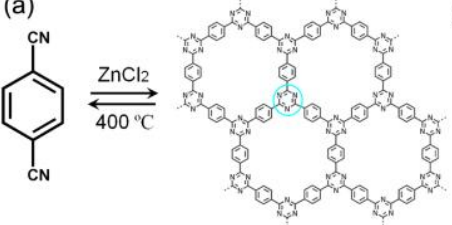

(b)

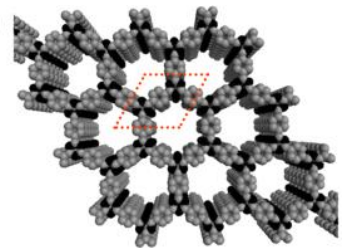

Fig. 6 (a) Trimerization of dicyanobenzene under ionothermal conditions to a covalent triazine-based framework (CTF-1); (b) schematic representation of the structure of CTF-1 (C gray, $\mathrm{N}$ black). (Adapted with permission from ref. 42. Copyright 2008 Wiley-VCH.).

The dynamic trimerization reaction is taking place under ionothermal conditions, which results in the formation of $\mathrm{C}_{3} \mathrm{~N}_{3}$ rings (indicated by a circle). These $\mathrm{C}_{3} \mathrm{~N}_{3}$ rings further act as triangle nodes for the connection of phenyl groups. The extensive connectivity of $\mathrm{C}_{3} \mathrm{~N}_{3}$ and phenyl rings gives rise to continuous sheet layer network. The sheets after geometry optimization are assembled into an eclipsed AAA structure, in which the atoms of each layer are placed above their analogues in the next layer (Fig. $6 \mathrm{~b})$. The crystalline structure of triazine-based organic framework (CTF-1) with hexagonal packing of pores is evidenced by the intense XRD peaks. The sheetlike structure of CTF-1 in hcb net (indicated by rhombus shape) resembles nicely the boron oxide based covalent organic frameworks (COF-1) due to their isoelectronic characteristics. The porosity of CTF-1 is probed by $\mathrm{N}_{2}$ sorption. The results show that a surface area of $791 \mathrm{~m}^{2} \mathrm{~g}^{-1}$ and a total pore volume of $0.40 \mathrm{~cm}^{3} \mathrm{~g}^{-1}$ are obtained for CTF-1 product. From the pore size distribution determined by NL-DFT, a pore size of $1.2 \mathrm{~nm}$ is found in CTF-1 structure, which is in agreement with the pore size estimated from the optimized model. Shortly later, the same research group rationally extended the family member to a new triazine-based framework (CTF-2) from the perspective of hcb topology. CTF-2 is built up from 2,6dicyanonaphthalene, exhibiting regular pore size of $2.0 \mathrm{~nm}^{43}$ The physicochemical properties of the porous covalent triazine-based frameworks are further investigated deeply by our colleagues. ${ }^{44-50}$ The CTF-type materials are good candidates as nanostructured

Table 1 A summary of 2D POF materials with various monomers, underlying topologies and final structures with diversified applications. $A_{2}, A_{3}, A_{4}, B_{2}$, $\mathrm{B}_{3}$ refers to the organic monomers with 2,3 or 4 -nodes.

\begin{tabular}{|c|c|c|c|c|}
\hline $\begin{array}{l}\text { Monomer } \\
\text { type }\end{array}$ & $\begin{array}{c}\text { Bond } \\
\text { connectivity }\end{array}$ & $\begin{array}{c}\text { Underlying } \\
\text { topology/structure }\end{array}$ & Application & Ref. \\
\hline $\begin{array}{c}\mathrm{A}_{2} \\
\mathrm{~A}_{2}+\mathrm{B}_{3} \\
\mathrm{~A}_{3}+\mathrm{B}_{2}\end{array}$ & $\mathrm{~B}-\mathrm{O}$ & $\begin{array}{l}\text { hcb; COF-1, COF-5, COF- } \\
\quad 6, \text { COF- } 8 \text {, COF-10 }\end{array}$ & $\begin{array}{c}\text { Storage of } \mathrm{H}_{2}, \mathrm{CH}_{4}, \mathrm{CO}_{2} \text { and } \mathrm{NH}_{3} \text {, } \\
\text { Thin films, Luminescence and } \\
\text { semiconductors }\end{array}$ & $\begin{array}{l}17,27,28,29,33, \\
41,34,38,39,40\end{array}$ \\
\hline $\begin{array}{c}\mathrm{A}_{2} \\
\mathrm{~A}_{3} \\
\mathrm{~A}_{3}+\mathrm{B}_{2}\end{array}$ & $\mathrm{C}-\mathrm{N}$ & $\begin{array}{l}\text { hcb; CTF-1, CTF-2, CTFs, } \\
\text { PAF-6, CIN, COF-LZU1, } \\
\text { COF-42, COF-43 }\end{array}$ & $\begin{array}{c}\mathrm{H}_{2} \text { sorption, Fluorescence, Catalysis, } \\
\text { Drug delivery }\end{array}$ & $\begin{array}{l}42,43,44,67,45, \\
46,48,72,73,51, \\
\quad 52\end{array}$ \\
\hline $\begin{array}{c}\mathrm{A}_{3} \\
\mathrm{~A}_{3}+\mathrm{B}_{2} \\
\mathrm{~A}_{2}+\mathrm{B}_{3}\end{array}$ & $\begin{array}{l}\mathrm{C}-\mathrm{C}, \\
\mathrm{B}-\mathrm{N}\end{array}$ & $\begin{array}{l}\text { hcb; COP-1, CMPs, JUC- } \\
\text { Z2, PAF-5, BLP-2 }\end{array}$ & $\begin{array}{c}\text { Storage of } \mathrm{H}_{2} \text { and } \mathrm{CO}_{2} \text {, Electrodevices } \\
\text { or sensors, Adsorbents for organic } \\
\text { pollutants, Catalysis }\end{array}$ & $\begin{array}{l}53,54,56,57,59, \\
\quad 70,55,58,71\end{array}$ \\
\hline $\mathrm{A}_{4}+\mathrm{B}_{2}$ & $\begin{array}{l}\mathrm{B}-\mathrm{O}, \\
\mathrm{C}-\mathrm{N}, \\
\mathrm{C}-\mathrm{C}\end{array}$ & $\begin{array}{l}\text { sql; Pc-PBBA COF, COF- } \\
\text { 366, COF-66, FeP-CMP, } \\
\text { Fe-POPs }\end{array}$ & $\begin{array}{c}\text { Photoluminescence, } \\
\text { Electronics/optoelectronics, Catalysis, } \\
\mathrm{CO}_{2} \text { adsorption }\end{array}$ & $60,61,62,63,64$ \\
\hline
\end{tabular}


supports for liquid-phase catalytic reactions thanks to their high porosity and high thermal stability. ${ }^{46,48}$ Highly dispersed and active palladium nanoparticles were stabilized in the nitrogendoped porous frameworks. The results showed that the performance of Pd supported on the CTFs surpassed that on the activated carbon for the selective oxidation of alcohols.

With the same principle that $\mathrm{A}_{3}$ (triangle units) and $\mathrm{B}_{2}$ (linear units) generally yield molecular networks in hcb topology, we recently synthesized a $2 \mathrm{D}$ semicrystalline porous aromatic framework (PAF-6) using cyanuric chloride and piperazine as the initial reactants. ${ }^{51}$ The reaction was performed via a one-step polymerization, as depicted in Fig. 7a. The regularity of the structure was further studied by powder XRD, which is a general technique for the determination of crystallinity. Many strong peaks were observed in the XRD pattern (Fig. 7b), providing a sound proof that PAF-6 was obtained in a crystalline phase. To explore the possible structure of PAF-6, we modeled the structure on Materials Studio (MS) and carried out Focite force-field calculations. The computation result reveals that the planar triazine and chair-form piperazine construct covalent sheets with waves; and the sheets prefer packing at a specific angle to form the expected hcb-type network. The aligned tubular channels result in a pore with a diameter of $11.5 \times 12.6 \AA$. PAF- 6 was further exploited as a good drug carrier for ibuprofen drug delivery. This example shows a typical case of the designed synthesis of POFs from the topological perspective. However, it is a pity that as-prepared material is semicrystalline,

(a)
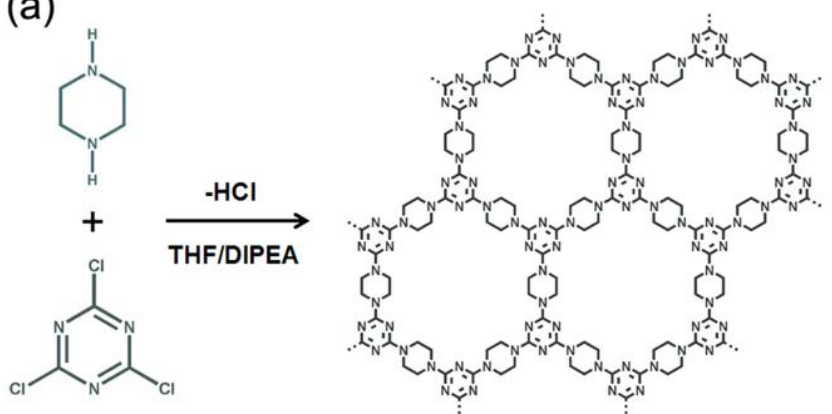

(b)

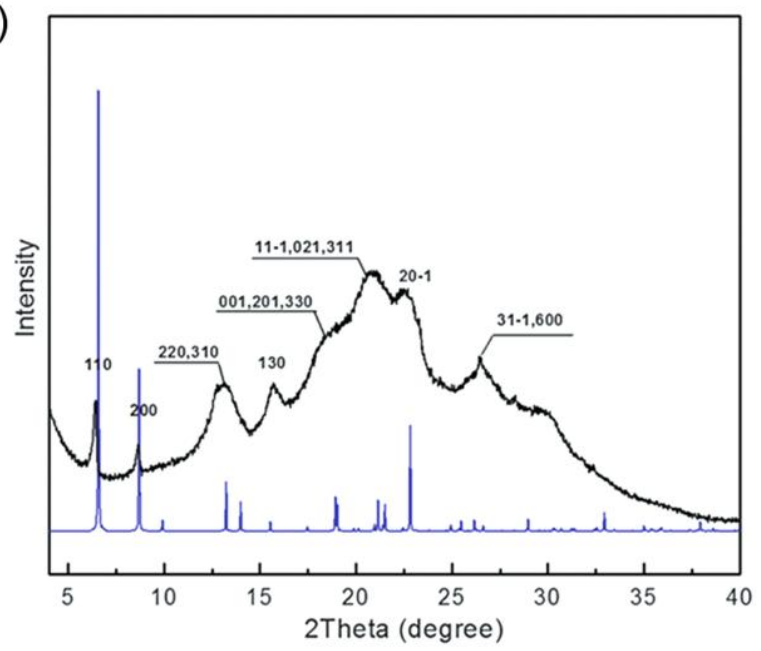

Fig. 7 (a) The synthesis route and network of PAF-6, (b) experimental (black) and calculated (blue) XRD patterns for PAF-6. because there is an amorphous phase in the sample to some extent. Other success of the preparation of $\mathrm{C}-\mathrm{N}$ bonded hydrazone compound was also made. ${ }^{52}$

Recently, hcb-based POF materials can be also successfully synthesized via formation of $\mathrm{C}-\mathrm{C}$ or $\mathrm{B}-\mathrm{N}$ covalent bonds between a variety of monomers (Table 1 ) through viable polymerization routes (i.e. cross-coupling reaction). ${ }^{53-59}$ Further attention was paid to the extensive studies of gas/liquid sorption ${ }^{54,59}$ and semiconductivity. In particular, the $\mathrm{H}_{2}$ uptake of $1.67 \mathrm{wt} \%$ was obtained for lithium-modified covalent-organic polymer at $\mathrm{T}=77$ $\mathrm{K}$ and $\sim 1$ bar. $^{53}$ The conjugated microporous polymer (CMP-1) network showed a very high volumetric $\mathrm{CO}_{2}$ uptake at $298 \mathrm{~K}$ and 1 bar, adsorbing $1.18 \mathrm{mmol} \mathrm{g}^{-1}$ of $\mathrm{CO}_{2}{ }^{56-57}$ Porous aromatic framework material (PAF-5) displayed huge uptake for adsorbing volatile organic compounds (1286, 949 and $1114 \mathrm{mg} \mathrm{g}^{-1}$ at $298 \mathrm{~K}$ for benzene, methanol and toluene, respectively). ${ }^{58}$ Microporous organic polymer (JUC-Z2) with an hcb topology was found to possess an electroactive framework and exhibit electrochemical ion recognition, which is beneficial for typical p-type semiconductors. ${ }^{55}$

As stated in the introduction section, the relative geometry of building blocks plays an important role in the determination of the topology of final structure. Based on this consideration, when square monomers with four nodes are employed for the synthesis of POFs; the final topology of square lattice (sql) would be constructed. Dichtel etc. reported the preparation of a new POF that features a square lattice composed of phthalocyanine macrocycles $(\mathrm{Pc})$ joined by phenylene bis(boronic acid) linkers (Fig. 8). ${ }^{60-61}$ This process was realized by a Lewis acid-catalyzed protocol to form boronate esters directly from protected catechols and arylboronic acids. This transformation also provides crystalline boronate ester-linked COFs from protected polyfunctional catechols and bis(boronic acids) (PBBA). The crystalline nature of this COF material was confirmed by XRD. After the refinement of the measured XRD pattern profile in the Materials Studio, the unit-cell parameters are produced, which gives great help in the visualization of the arrangement of phthalocyanine units. It was found that phthalocyanines had a strong tendency to stack cofacially in an eclipsed sql fashion within the COF structure (Fig. 8b). This assembly gives rise to form $2.3 \mathrm{~nm}$ pores that run parallel to the stacked building blocks. The nitrogen-gas adsorption measurement shows that Pc-PBBA COF possesses high Langmuir surface area of $506 \mathrm{~m}^{2} \mathrm{~g}^{-1}$ and a maximum pore volume of $0.258 \mathrm{~cm}^{3} \mathrm{~g}^{-1}$. More interestingly, this COF material with incorporation of chromophores in the


Fig. 8 (a) The formation process of an eclipsed 2D Pc-PBBA COF that consists of phthalocyanines linked by PBBA with Lewis acid catalyst; (b) Pc-PBBA COF exhibits a square lattice with 2D sheets that form eclipsed stacks. (Reprinted with permission from ref. 60. Copyright 2010 Nature Publishing Group.). 
framework exhibits unique photoluminescence property.

Other researchers forward the synthesis of this series of sqlbased porous POF materials (e.g. porphyrin derivatives) and explore the potential applications in electronics with high charge carrier mobility, ${ }^{62}$ heterogeneous catalysis, ${ }^{63}$ and $\mathrm{CO}_{2}$ sequestration. ${ }^{64}$ Typically, two new 2D COFs (COF-366, COF-66) with pore sizes of 2.0 and $2.3 \mathrm{~nm}$, possess extraordinarily high one-dimensional hole mobilities of 8.1 and $3.0 \mathrm{~cm}^{2} \mathrm{~V}^{-1} \mathrm{~s}^{-1}$, respectively. These $\mathrm{COF}$ materials with high charge carrier mobilites are believed to be representative compounds for designing viable plastic electronics and optoelectronic systems. ${ }^{62}$ As-prepared conjugated microporous metalloporphyrin-based polymer (FeP-CMP) was developed as a catalytic scaffold for the activation of molecular oxygen to convert sulfide to sulfoxide. A large surface area of $1270 \mathrm{~m}^{2} \mathrm{~g}^{-1}$ facilitates the transformation reaction with high conversion (up to 99\%), selectivity (up to 99\%) and a large turnover number. ${ }^{63}$ Another example of Iron containing porous organic polymers (Fe-POPs) was presented for outstanding adsorption capacity for $\mathrm{CO}_{2}(\sim 19 \mathrm{wt} \%$ at $273 \mathrm{~K}$ and 1 bar) ${ }^{64}$ In conclusion, the design and synthesis of $2 \mathrm{D}$ porous organic frameworks with regular pore systems and high surface areas by the utilization of topology chemistry, is in the endless pursuit. ${ }^{65-69}$ The group of POFs with intrinsic active sites can directly interact with other molecules (for instance gas adsorption or heterogeneous catalysis), ${ }^{70-71}$ and also can be served as good hosts for supporting different species. ${ }^{72-73}$

\subsection{Three-dimensional POFs}

Different from low-dimensional and 2-dimensional POFs (2D), there remain big practical and conceptual challenges for construction of 3-dimensional (3D) ordered POF materials. The exploitation of $3 \mathrm{D}$ extended structures is of great interests due to a number of possible structures resulted from linking specific building-unit geometries, which would be our next focus. Generally speaking, polyhedra are required for the construction of 3D framework. These polyhedra are connected with planar SBUs or each other to form extended structures (Fig. 9).

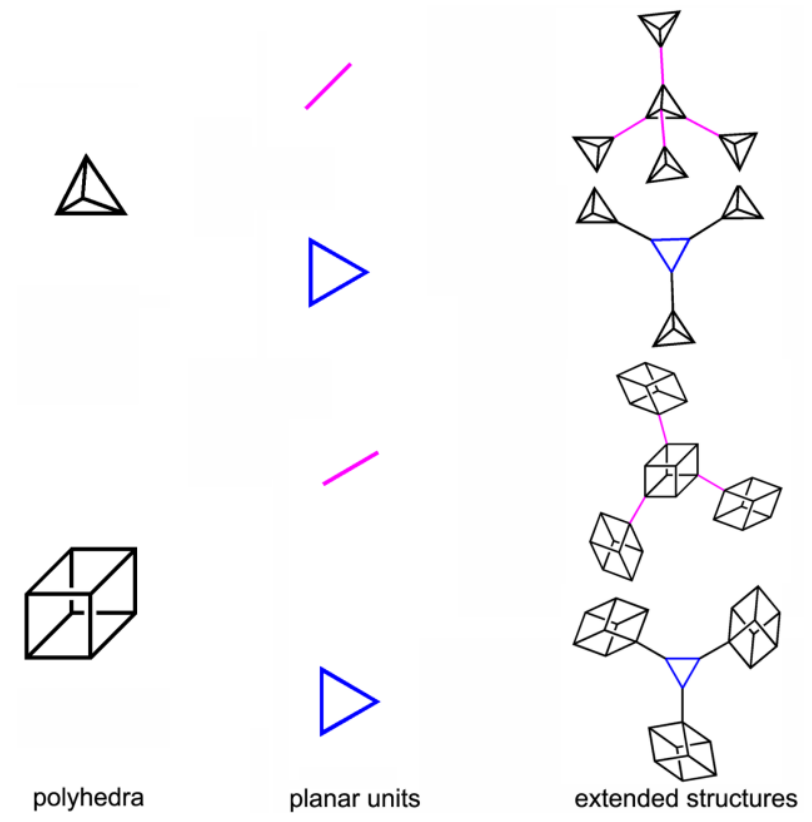

Fig. 9 Building blocks and their corresponding structures.
In this section, we will introduce the crystalline, semicrystalline, and some non-crystalline but short-range ordered 3D POFs. The pioneer work of rational design for 3D COFs has been achieved by Yaghi etc. by judiciously choosing building blocks and using reversible condensation reactions. ${ }^{74}$ To figure out the most possible 3D structure, triangular (3-nodes) and tetrahedral (4nodes) shaped monomers are selected and targeted for the synthesis of 3D COFs. In planning the synthesis, they chose the tetrahedral building blocks of tetra(4dihydroxyborylphenyl)methane (TBPM) and its silane analog (TBPS), and triangular hexahydroxytriphenylene (HHTP) (Fig. $10 \mathrm{a}-\mathrm{c})$ based on the design principles of reticular/topological chemistry. Dehydration reactions of these units produce triangular $\mathrm{B}_{3} \mathrm{O}_{3}$ rings and $\mathrm{C}_{2} \mathrm{O}_{2} \mathrm{~B}$ rings (Fig. $10 \mathrm{~d}$ and e). After geometry optimization and energy minimization assisted with computation means (Cerius software, force-field calculations), two preferred nets of ctn (Fig. 10f) and bor (Fig. 10g) are envisioned via self-condensation of tetrahedral blocks (Fig. 10a and b) and co-condensation with the triangular units (Fig. 10c). After careful experimental manipulation, crystalline 3D COFs termed as COF-102, COF-103, COF-105 (ctn-type) and COF108 (bor-type) are produced;

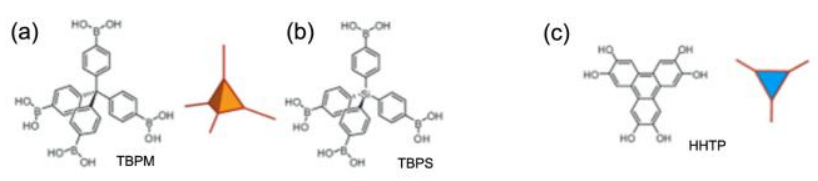

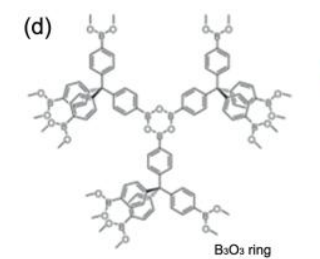

(f)
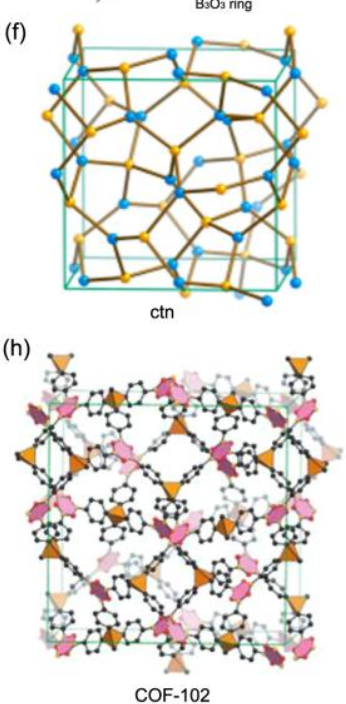

(e)

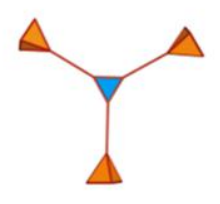

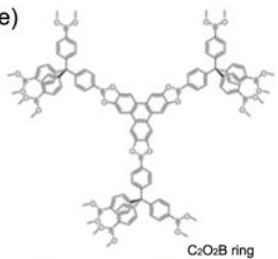

(g)

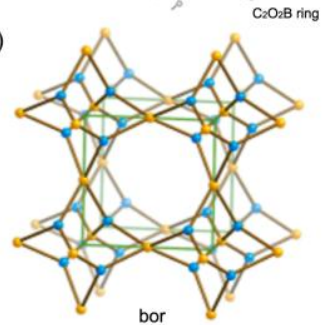

bor

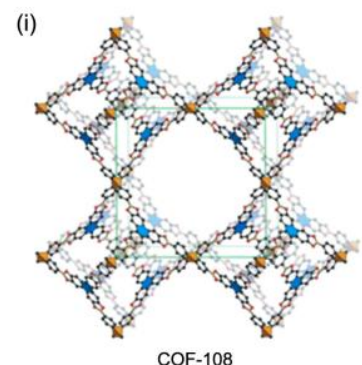

Fig. 10 Boronic acids are shown as tetrahedral building units (a) and (b), and a planar triangular unit (c) is also shown (polyhedron in orange and triangle in blue, respectively) including fragments revealing the $\mathrm{B}_{3} \mathrm{O}_{3}(\mathrm{~d})$ and the $\mathrm{C}_{2} \mathrm{O}_{2} \mathrm{~B}$ (e) ring connectivity in the expected linked products via condensation routes. The represented topological nets of ctn (f) and bor (g); atomic connectivity and structure of crystalline products of COF-102 (h) and COF-108 (i). Carbon, boron, and oxygen atoms are represented as gray, orange, and red spheres, respectively. (Adapted with permission from ref. 74. Copyright 2007 AAAS.). 
and the derived structures of crystalline products of COF-102 and COF-108 are shown in Fig. 10h and i. It is also of interest to consider their porous structures. In the COFs with ctn nets, the center of the largest pore in COF-102, COF-103, and COF-105 is 5.66, 5.98, and $10.37 \AA$ respectively. In the case of bor-type COF, COF-108 has two cavities of 9.34 and $15.46 \AA$. The large effective pore size allows a high probability for the formation of bor structure due to its low density. Thus, bor-based COF-108 has a remarkably low density of $0.17 \mathrm{~g} \mathrm{~cm}^{-3}$ (the densities of other COFs: $0.41 \mathrm{~g} \mathrm{~cm}^{-3}$ for COF-102, $0.38 \mathrm{~g} \mathrm{~cm}^{-3}$ for COF-103, $0.18 \mathrm{~g} \mathrm{~cm}^{-3}$ for COF-105). As-prepared COF materials also have exceptionally high surface areas of 3472 and $4210 \mathrm{~m}^{2} \mathrm{~g}^{-1}$ for COF-102 and COF-103 respectively, calculated from the Brunauer-Emmett-Teller (BET) model.

Subsequently, we have tried to synthesize the ctn-topological porous aromatic frameworks (PAFs) by substituting central atoms of $\mathrm{C}$ and $\mathrm{Si}$ with $\mathrm{Ge}$ in the skeleton. ${ }^{75-76}$ This $3 \mathrm{D}$ PAF-14 possess high BET surface area of $1288 \mathrm{~m}^{2} \mathrm{~g}^{-1}$ and interesting fluorescence property. As-designed PAF-14 with a crystalline polymeric backbone exhibits a high fluorescence quenching ability for hazardous explosives, such as nitrobenzene, 2,4-DNT (2,4dinitrotoluene) and TNT (2,4,6-trinitrotoluene). Other alternative organic monomers with longer linkers are also employed for the formation of highly symmetrical ctn-topology based POF architectures. ${ }^{77-78}$

Later on, we have developed a bottom-up route for the targeted synthesis of 3D PAF materials with ctn-topology. ${ }^{79}$ The initial monomer is tetrakis(4-cyanophenyl)methane. With a close inspection, we have found that this monomer is a rigid tetrahedral building block (Fig. 11a). Moreover, trimerization reaction of the building units can produce triangular $\mathrm{C}_{3} \mathrm{~N}_{3}$ rings (Fig. 11b), which serve as triangular building units. Three tetrahedral units $\left(\mathrm{A}_{4}\right)$ are linked together by a planar triangular ring $\left(\mathrm{B}_{3}\right)$ to form a secondary building unit (Fig. 11c and d). Linking tetrahedral and triangular building units can favorably generate ctn and bor nets. With the simulation with Materials Studio followed by energy minimization, the building up of ctn and bor nets would be visualized by fitting both tetrahedral (tetraphenylmethane) and triangular $\left(\mathrm{C}_{3} \mathrm{~N}_{3}\right.$ ring $)$ building units on the corresponding nodes (Fig. 11e and f). To facilitate the formation of 3D extended frameworks, an effective synthesis reaction called ionothermal reaction was carried out. Under the catalysis of $\mathrm{ZnCl}_{2}$, three aromatic nitrile groups have been trimerized to form the $\mathrm{C}_{3} \mathrm{~N}_{3}$ triazine ring. Tetraphenylmethane and the $\mathrm{C}_{3} \mathrm{~N}_{3}$ triazine ring were connected with each other via strong covalent bonds to construct a three-dimensional organic open framework (designated as PAF2). XRD characterization shows that as-synthesized sample is noncrystalline. Although PAF-2 lacks of crystallinity, the pore periodicity was determined by nitrogen physical sorption. The pore size distribution calculated from nonlinear density functional theory (NL-DFT) gives a value about $1.06 \mathrm{~nm}$. (a)

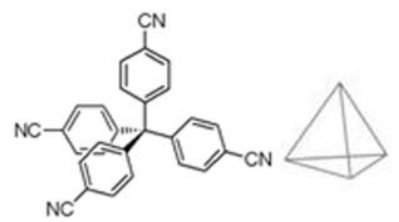

(c)

(e)
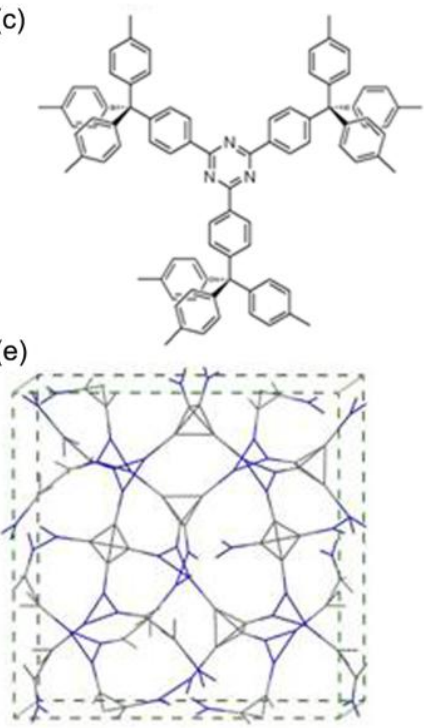

(b)<smiles>Cc1nc(C)nc(C)n1</smiles>

(d)

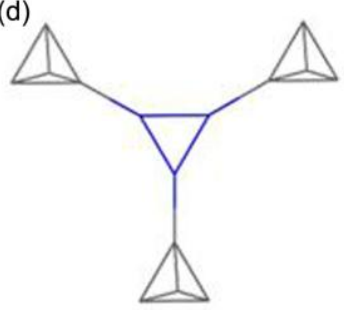

(f)



Fig. 11 The designed synthesis process for PAF-2. Tetrakis(4cyanophenyl)-methane is chosen as the tetrahedral building unit (a) and a planar triangular $\mathrm{C}_{3} \mathrm{~N}_{3}$ ring (b) is produced by trimerization reaction (polyhedron in light gray and triangle in blue, respectively). A secondary building unit is formed by linking three tetrahedral units with the planar triangular ring, (c) and (d). These building units connected together can produce the expanded ctn (e) and bor (f) nets, respectively.

Table 2 A summary of 3D POF materials with various monomers, underlying topologies and final structures with diversified applications. $\mathrm{A}_{4}, \mathrm{~A}_{8}, \mathrm{~B}_{2}, \mathrm{~B}_{3}$ refers to the organic monomers with $4,8,2$ or 3 -nodes.

\begin{tabular}{|c|c|c|c|c|}
\hline $\begin{array}{c}\text { Monomer } \\
\text { type }\end{array}$ & $\begin{array}{c}\text { Bond } \\
\text { connectivity }\end{array}$ & $\begin{array}{c}\text { Underlying } \\
\text { topology/structure }\end{array}$ & Application & Ref. \\
\hline $\begin{array}{c}\mathrm{A}_{4} \\
\mathrm{~A}_{4}+\mathrm{B}_{3}\end{array}$ & $\begin{array}{l}\mathrm{B}-\mathrm{O}, \\
\mathrm{C}-\mathrm{N}, \\
\mathrm{C}-\mathrm{C}\end{array}$ & $\begin{array}{l}\text { ctn, bor; COF-102, COF- } \\
\text { 103, COF-105, COF-108, } \\
\text { COF-202, PAF-2, PAF-14, } \\
\text { PAF-15, PAF-16, PAF-18 }\end{array}$ & $\begin{array}{c}\text { Sensors for hazardous explosives, } \\
\text { Adsorbents for organics, } \mathrm{CO}_{2} \text { capture, } \\
\mathrm{H}_{2} \text { storage }\end{array}$ & $\begin{array}{c}74,75,76,77,78 \\
79,80,81,83,84 \\
85,104\end{array}$ \\
\hline $\begin{array}{c}\mathrm{A}_{4}, \\
\mathrm{~A}_{4}+\mathrm{B}_{2}\end{array}$ & $\begin{array}{l}\mathrm{C}-\mathrm{C}, \\
\mathrm{C}-\mathrm{N}\end{array}$ & $\begin{array}{c}\text { dia } \text { PAF-1, PAF-3, PAF- } \\
\text { 4, PAF-11, PAF-301, PAF- } \\
\text { 302, PAF-303, PAF-304, } \\
\text { COF-300, COF-301, TzFs, } \\
\text { PPNs, PONs, POPs, PPI, } \\
\text { DUT-37 }\end{array}$ & $\begin{array}{l}\text { Storage of } \mathrm{H}_{2}, \mathrm{CO}_{2} \text { and } \mathrm{CH}_{4}, \\
\text { Adsorbents for organics, } \\
\text { Microreactors, Catalysis }\end{array}$ & $\begin{array}{l}86,87,88,89,90 \\
91,92,93,94,100 \\
101,102,103,106\end{array}$ \\
\hline $\begin{array}{c}\mathrm{A}_{8} \\
\mathrm{~A}_{8}+\mathrm{B}_{2} \\
\end{array}$ & $\mathrm{C}-\mathrm{C}$ & $\begin{array}{c}\text { ACO, LTA; hybrid } \\
\text { polymer, JUC-Z1, PAF-12 }\end{array}$ & $\begin{array}{c}\mathrm{H}_{2} \text { sorption, Adsorbents for volatile } \\
\text { organic compounds }\end{array}$ & $96,98,99$ \\
\hline
\end{tabular}


The narrow pore size distribution and computation results provide a proof for ctn based structure of PAF-2. The apparent BET surface area was calculated to be $891 \mathrm{~m}^{2} \mathrm{~g}^{-1}$ and the pore volume was $0.54 \mathrm{~cm}^{3} \mathrm{~g}^{-1}$. In addition, PAF-2 material exhibits high hydrophobicity and aromaticity, the properties of which result in high selective adsorption towards benzene over cyclohexane. The syntheses of PAF-2 analogues have been continued using different organic monomers via forming $\mathrm{C}-\mathrm{N}$ or $\mathrm{C}-\mathrm{C}$ covalent bonds. ${ }^{80-81}$ Interesting properties of ctn and bor types of COFs and $\mathrm{PAFs}^{82}$ endow themselves with promising applications in gas adsorption (Table 2), especially for hydrogen storage. ${ }^{83-85}$ For example, the hydrogen storage capacity of some COF series can overpass the Department of Energy's target of $6 \mathrm{wt} \%$ at room temperature. $^{78,85}$

Highly porous POF materials with stable structures are greatly demanded with respect to advanced applications. It is well known that one of the most stable compounds in nature is diamond, in which each carbon atom is tetrahedrally connected to four neighboring atoms by covalent bonds (Fig. 12a). ${ }^{86}$ Conceptually, an insertion of specific linkers between $\mathrm{C}-\mathrm{C}$ bonds in materials is possible to create porosity. In this way, the replacement of C-C covalent bonds with rigid phenyl rings could not only retain a diamond-like structural stability, but also allow sufficient exposure of the faces and edges of phenyl rings; thus, enhanced internal surface area and low framework density are expected. We have performed computational studies using a multiscale theoretical method. We have found that replacement of the C-C bond with one phenyl group (Fig. 12b) can result in P1 structure with a BET surface area of $1880 \mathrm{~m}^{2} \mathrm{~g}^{-1}$ assuming the preservation of diamondoid topology. Addition of two phenyl rings to the C-C bond (Fig. 12c) can almost triple the BET surface area $\left(5640 \mathrm{~m}^{2}\right.$ $\mathrm{g}^{-1}$ ) as well as significantly reducing the density of the structure (denoted as P2). Further insertion of three phenyl rings in the C-C bond (Fig. 12d), however, will enlarge the pore sizes of the P3 structure to the mesoscale range. Based on the computational design, we focus on the synthesis of porous PAF materials with targeted P2 structure. (a)

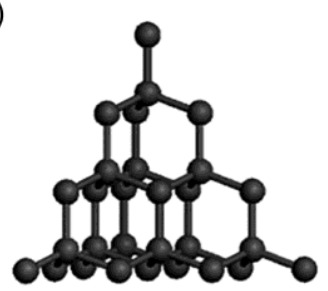

(c)

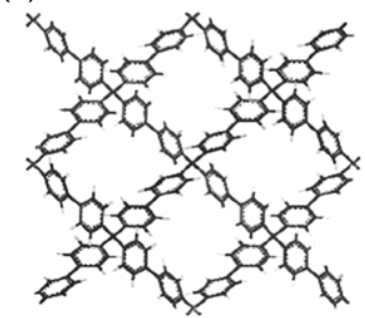

(b)

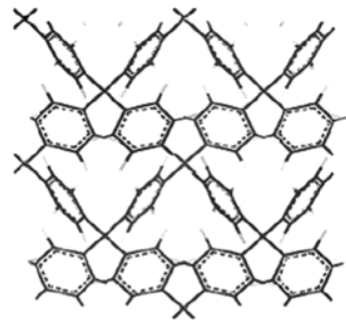

(d)



Fig. 12 The structure of diamond (a); and the structure models of P1 (b), P2 (c) and P3 (d).
Starting from the point of diamond topology (dia), we are motivated to seek a top-down approach to synthesize PAF materials with dia nets. Therefore, tetrakis(4-bromophenyl) methane was selected as the tetrahedral building unit, and the phenyl rings were coupled using Yamamoto-type Ullmann reaction to synthesize $\mathrm{P} 2$. Due to the irreversibility of the reaction, PAF-1 in crystalline state was not obtained. However, some characteristic XRD peaks and pore regularity prove that the preferential topology of PAF-1 is dia, which is confirmed by computational study. Further, PAF-1 represents an important member of POFs originated from topological concepts. Assynthesized compound shows extraordinarily high apparent surface area of $5600 \mathrm{~m}^{2} \mathrm{~g}^{-1}$; and exceptional thermal and hydrothermal stabilities. These superior properties make PAF-1 a very attractive candidate for gas storage applications, particularly for hydrogen storage (absolute uptake of $10.7 \mathrm{wt} \%$ at 48 bar and $77 \mathrm{~K}$ ) and carbon dioxide capture (uptake of $1300 \mathrm{mg} \mathrm{g}^{-1}$ at 40 bar and room temperature), which are related to clean energy issues. We have extended the work to the synthesis of other types of dia-based POF materials by employing elongated organic monomers. ${ }^{87-88}$ Meanwhile, other groups have also made explosive attempts in the designed synthesis with different connectivity, ${ }^{89}$ characterization $^{90}$ and exploitation for advanced applications of dia-type POFs, ${ }^{91-95}$ which are summarized in Table 2.

Zeolite-type POFs are attractive in the family of porous materials, owing to their high thermal stability, more optional connectivity (e.g. octahedral) and versatile crystalline structures. These merits motivate us to advance the synthesis of other topology-based POFs. In the following, we will present the rational synthesis of two typical zeolitic POFs (namely ACO and LTA types). Double four rings (D4R) are commonly known as the crystal growth units for ACO, LTA-type zeolites (Fig. 13). Linking D4R along the octant direction can generate LTA and ACO nets in almost equal opportunity (Fig. 13). Cubic octameric siloxane cages $\left(\mathrm{Si}_{8} \mathrm{O}_{12}\right)$ have also been widely utilized for the synthesis of inorganic-organic hybrid porous materials by directly linking functionalized D4R with rigid organic linkers. Connecting the nodes with sterically bulky or short linkers can prevent the interpenetration of local networks, which is most likely to result in crystalline porous solids with defined topology. The group of Okubo have reported the self-polymerization of bromophenylethenyl-terminated cubic D4R siloxane cages

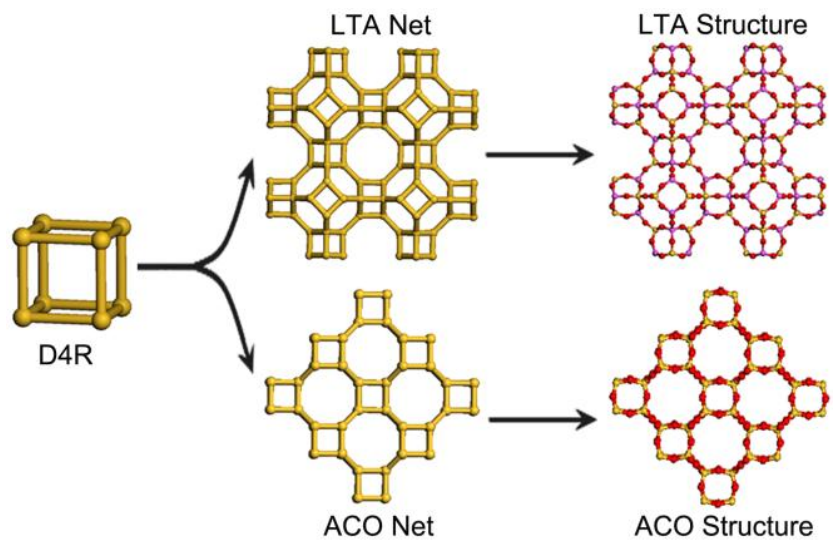

Fig. 13 The building process of LTA and ACO structures. 
(BrPh-D4R) by nickel-mediated Yamamoto reaction (Fig. 14). ${ }^{96}$ As a result of the shortened linker (phenylethenyl group), the obtained polymer (Fig. 14) would exhibit less pronounced network interpenetration, and thereby more uniform pore size distribution and higher structural periodicity. Besides, as D4R cages are very rigid, connecting the D4R units through twocoordinated linear linkers would result in the ACO zeolitic topology as a default structure. To verify this assumption, the hybrid polymer was subjected to X-ray diffraction characterization (XRD). The XRD pattern in Fig. 14b shows three broad peaks centered at $2 \theta=5.0,10.0$, and $20.7^{\circ}$, equivalent to d-spacing distances of $17.6,8.9$, and $4.3 \AA$, respectively. The large d-spacing of $17.6 \AA$ is likely attributed to the periodic arrangement of the D4R cages linked by ethenylenephenylene bridges. The strong peaks at $2 \theta=5.0$ and $10.0^{\circ}$ would arise from (110) and (220) planes, respectively, as a lattice parameter of the model constructed based on ACO topology is about $25 \AA$. Nitrogen adsorption measurement points out this hybrid polymer possesses porous nature with BET surface areas of $1045 \mathrm{~m}^{2} \mathrm{~g}^{-1}$ and a total pore volume of $1.01 \mathrm{~cm}^{3}$ $\mathrm{g}^{-1}$. The pore diameter of $11.6 \AA$ with narrow and sharp distribution is determined by the NL-DFT method. Other attempts are also made in order to synthesize ACO topology based microporous POF materials. ${ }^{97}$
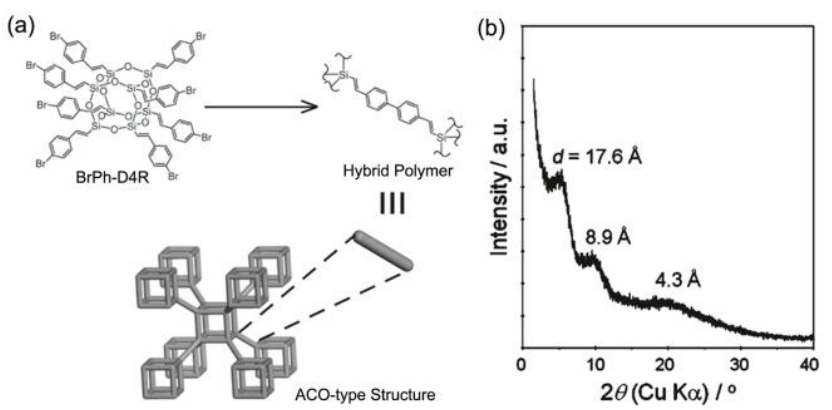

Fig. 14 (a) Schematic design of the hybrid polymer built by $\mathrm{Ni}^{0}$-mediated Yamamoto polymerization of the BrPh-D4R cages, and (b) the powder XRD pattern of the hybrid polymer. (Reprinted with permission from ref. 96. Copyright 2010 American Chemical Society.).

As illustrated in Fig. 13, it is well known that D4R are secondary building units in the construction of LTA-type zeolite. The zeolite unit cell contains 24 tetrahedrally coordinated $\mathrm{T}$ atoms to form truncated octahedra ( $\beta$-cages) and truncated cuboctahedra ( $\alpha$-cages), the cages of which are linked by D4R. This unique LTA topology with two types of cages has inspired us to make attempts for the construction of new POF materials that share the same zeolitic topology. For this target, we innovated a bottom-up synthesis approach for designated as JUCZ1 (Fig. 15). ${ }^{98}$ The monomer unit, p-iodiooctaphenylsilsesquioxane (I8OPS), is a cubic nano-building block, such that each octant in Cartesian space contains one functional iodine group. After being treated by traditional Ullmann chemistry methods, biphenyl groups were formed to alternate the T-O-T linkage between double-4-rings in LTA or ACO backbones. With full consumption and careful manipulation of experiments, octaphenylsilsesquioxanes (OPSs) have a big chance to form a two-cage LTA structure. The crystalline structure and porous characters of JUC-Z1 are followed by XRD and $\mathrm{N}_{2}$ sorption measurements.

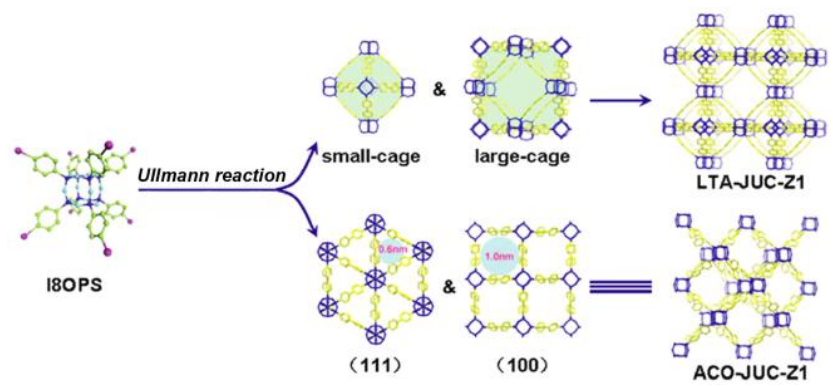

Fig. 15 The strategy for the synthesis of a covalently-linked microporous organic-inorganic hybrid framework JUC-Z1 from I8OPS via an Ullmann reaction with a LTA or ACO topology ( $\mathrm{Si}$ is illustrated in blue, $\mathrm{O}$ in cyan, $\mathrm{C}$ in green and $\mathrm{I}$ in purple for I8OPS).

The XRD pattern shows that a semicrystalline product is obtained. A main peak at $7.8^{\circ}$ is observed, corresponding to a d-spacing distance of $11.3 \AA$, which is arising from the (200) plane of LTAJUC-Z1 model. The pore size distribution calculated from NLDFT theory shows that only two clear narrow distributed peaks of 11.6 and $20.0 \AA$ are observed, which could be attributed to the pore size distribution of $\alpha$-cage and $\beta$-cage compared with the LTA model (14.9 and $21.8 \AA$ ). According to the pore size distribution, we propose that the structure of as-synthesized material has the possibility of affording an LTA net. Subsequently, we have also achieved the synthesis of another micro-mesoporous inorganic-organic hybrid material PAF-12 with longer rigid linker via Suzuki cross-coupling reaction with octaphenylsilsesquioxane (OPS, $\left.\left[\mathrm{C}_{6} \mathrm{H}_{5}\left(\mathrm{SiO}_{1.5}\right)\right]_{8}\right)$ as basic building units and 1,4-phenyldiboronic acid. ${ }^{99}$ The XRD study proves that PAF-12 shares LTA topology. According to argon sorption isotherm, the network of PAF-12 shows classic type IV isotherm and also exhibits a sharp uptake at low relative pressures, indicating micro-mesoporous texture. The pore size distribution of PAF-12 calculated from NL-DFT theory gives only two clear narrow peaks centered at 1.57 and $3.17 \mathrm{~nm}$. Given the aromatic framework and high porosity of JUC-Z1 and PAF-12, both materials were tested for adsorbing organic vapors such as benzene, methanol; which promise greatly potential for further environmental applications. In summary, pervasive studies (Table 2) have been contributed to the research field of the design and synthesis of 3D POF materials from the topology-point of view for diversified applications including gas sorption, ${ }^{100-105}$ and catalysis. ${ }^{106}$

\section{Conclusions and Outlook}

POFs are composed of pure organic units containing light elements, which are different from their counterparts of zeolite and MOFs. Since first discovered in 2005, POFs are emerging as a new generation of nanoporous materials. In more recent years, a rapid development in the synthesis of POFs is undergoing, which is witnessed by an even more remarkable growth rate of surface area in POFs than equivalent advances in MOFs. ${ }^{107-109}$ In this paper, we present the general ideas for the construction of POF materials from the perspective of topology chemistry. The underlying topologies play an important role in the targeted synthesis for POFs with predictable properties, because they magically unit the building blocks and structures into a perfect entity. One, two, three-dimensional POFs with recognized 
topological nets have been described consecutively through the context. We also provide a guideline for the design and synthesis of POFs from bi-direction pathways (top-down and bottom up) after careful examinations of preferred topologies. In addition to the concept of designed synthesis, the fascinating applications have also been introduced thanks to the superior properties of POFs, such as low framework density, ordered porous structures, high surface areas and porosity, and versatile building units in the architectures. POFs have found their wide applications in gas adsorption/storage, optic/electric devices, catalysis and biomedicine.

This paper has just summarized the state-of-the-art development on the design, synthesis, property, and application of porous organic frameworks from the point of view of topology chemistry. With fast-growing and further developing of POF materials, new avenues and opportunities will be opened and provided in this research field. To date, only several types of topological nets including quasiregular chain, hcb, sql, ctn, bor, dia, ACO, LTA; have been discovered among all the dimensionality. Therefore, new nets are highly desired, because different topologies would result in different structures and interesting properties of POFs. In this regard, great efforts are expected to be made towards the synthesis of new types of building units or starting organic monomers with various functionalities. Furthermore, new synthetic approaches or reaction types are needed to fulfill the requirements for the polymerization of monomers. Secondly, advanced and sophisticated characterization techniques are still in urgent need to gain more detailed information on the structures of POFs. The in-depth and comprehensive understanding of POF structures will help us to better synthesize POF materials in a more rational way. Moreover, computational simulation would assist us for the targeted synthesis of new materials. Thirdly, appropriate functional POF materials with high performances, high stabilities and selectivities are expected to be innovated for some specific uses. The further exploitation of potential applications will boost a great progress in the field of porous organic framework materials. In short, we may have just seen the tip of the iceberg in respect to POF materials. Extensive studies are underway and the future of the field is very appealing.

\section{Acknowledgements}

We are grateful for the financial support of National Basic Research Program of China (973 Program, grant nos. 2012CB821700), Major International (Regional) Joint Research Project of NSFC (grant nos.21120102034) and NSFC (grant nos. 20831002, 21201074).

\section{Notes and references}

${ }^{a}$ State Key Laboratory of Inorganic Synthesis and Preparative Chemistry, College of Chemistry, Jilin University, Changchun, China (130012). Tel/Fax: +86-431-85168331; E-mail: zhugs@jlu.edu.cn b Queensland Micro- and Nanotechnology Centre, Griffith University, Queensland, 4111, Australia.

1 R. R. Xu, W. Q. Pang, J. H. Yu, Q. S. Huo and J. S. Chen, Chemistry of Zeolites and Related Porous Materials; Wiley-Interscience, 2007.

2 V. Valtchev, S. Mintova and M. Tsapatsis, Ordered Porous Solids: Recent Advances And Prospects; Elsevier B. V.: Oxford, 2009.
3 Metal organic frameworks: Chem. Soc. Rev., 2009, 38, 1201; Chem. Rev., 2012, 112, 673.

4 X. Feng, X. S. Ding and D. L. Jiang, Chem. Soc. Rev., 2012, 41, 6010.

5 S. Y. Ding and W. Wang, Chem. Soc. Rev., 2013, DOI: $10.1039 / \mathrm{c} 2 \mathrm{cs} 35072 \mathrm{f}$.

6 N. B. McKeown and P. M. Budd, Macromolecules, 2010, 43, 5163.

7 A. Thomas, Angew. Chem. Int. Ed., 2010, 49, 8328.

8 T. Ben and S. L. Qiu, CrystEngComm, 2013, 15, 17.

9 A. I. Cooper, Adv. Mater., 2009, 21, 1291.

10 D. C. Wu, F. Xu, B. Sun, R. W. Fu, H. K. He and K. Matyjaszewski, Chem. Rev., 2012, 112, 3959.

11 Y. H. Jin, Y. L. Zhu and W. Zhang, CrystEngComm, 2013, DOI: 10.1039/C2CE26394G.

12 F. Vilela, K. Zhang and M. Antonietti, Energy Environ. Sci., 2012, 5, 7819.

13 E. Tylianakis, E. Klontzas and G. E. Froudakis, Nanoscale, 2011, 3, 856.

14 P. Kaur, J. T. Hupp and S. T. Nguyen, ACS Catal., 2011, 1, 819.

15 M. O'Keeffe, M. A. Peskov, S. J. Ramsden and O. M. Yaghi, Acc. Chem. Res., 2008, 41, 1782.

16 D. J. Tranchemontagne, J. L. Mendoza-Cortés, M. O'Keeffe and O. M. Yaghi, Chem. Soc. Rev., 2009, 38, 1257.

17 A. P. Côté, A. I. Benin, N. W. Ockwig, M. O’Keeffe, A. J. Matzger and O. M. Yaghi, Science, 2005, 310, 1166.

18 P. M. Budd, B. S. Ghanem, S. Makhseed, N. B. McKeown, K. J. Msayib and C. E. Tattershall, Chem. Commun., 2004, 230.

19 N. B. McKeown, P. M. Budd, K. J. Msayib, B. S. Ghanem, H. J. Kingston, C. E. Tattershall, S. Makhseed, K. J. Reynolds and D. Fritsch, Chem. Eur. J., 2005, 11, 2610.

20 R. S. Sprick, A. Thomas and U. Scherf, Polym. Chem., 2010, 1, 283.

21 C. D. Wood, B. Tan, A. Trewin, H. J. Niu, D. Bradshaw, M. J. Rosseinsky, Y. Z. Khimyak, N. L. Campbell, R. Kirk, E. Stöckel and A. I. Cooper, Chem. Mater., 2007, 19, 2034.

22 C. D. Wood, B. Tan, A. Trewin, F. F. Su, M. J. Rosseinsky, D. Bradshaw, Y. Sun, L. Zhou and A. I. Cooper, Adv. Mater., 2008, 20, 1916.

23 J. Schmidt, M. Werner and A. Thomas, Macromolecules, 2009, 42, 4426.

24 J. Ahn, W. J. Chung, I. Pinnau, J. S. Song, N. Y. Du, G. P. Robertson and M. D. Guiver, J. Membr. Sci., 2010, 346, 280.

25 M. G. Schwab, A. Lennert, J. Pahnke, G. Jonschker, M. Koch, I. Senkovska, M. Rehahn and S. Kaskel, J. Mater. Chem., 2011, 21, 2131.

26 Q. Chen, Q. Wang, M. Luo, L. J. Mao, C. G. Yan, Z. H. Li and B. H. Han, Polymer, 2012, 53, 2032.

27 A. P. Côté, H. M. El-Kaderi, H. Furukawa, J. R. Hunt and O. M. Yaghi, J. Am. Chem. Soc., 2007, 129, 12914.

28 H. Furukawa and O. M. Yaghi, J. Am. Chem. Soc., 2009, 131, 8875.

29 C. J. Doonan, D. J. Tranchemontagne, T. G. Glover, J. R. Hunt and O. M. Yaghi, Nat. Chem., 2010, $2,235$.

30 A. Nagai, Z. Q. Guo, X. Feng, S. B. Jin, X. Chen, X. S. Ding and D. L. Jiang, Nat. Commun., 2011, 2, 536.

31 J. W. Colson, A. R. Woll, A. Mukherjee, M. P. Levendorf, E. L. Spitler, V. B. Shields, M. G. Spencer, J. Park and W. R. Dichtel, Science, 2011, 332, 228.

32 R. W. Tilford, W. R. Gemmill, H. C. Loye and J. J. Lavigne, Chem. Mater., 2006, 18, 5296.

33 R. W. Tilford, S. J. Mugavero, P. J. Pellechia and J. J. Lavigne, $A d v$. Mater., 2008, 20, 2741.

34 J. F. Dienstmaier, A. M. Gigler, A. J. Goetz, P. Knochel, T. Bein, A. Lyapin, S. Reichlmaier, W. M. Heckl and M. Lackinger, ACS Nano, 2011, 5, 9737.

35 N. L. Campbell, R. Clowes, L. K. Ritchie and A. I. Cooper, Chem. Mater., 2009, 21, 204.

36 L. K. Ritchie, A. Trewin, A. Reguera-Galan, T. Hasell and A. I. Cooper, Microporous Mesoporous Mater., 2010, 132, 132.

37 M. Dogru, A. Sonnauer, A. Gavryushin, P. Knochel and T. Bein, Chem. Commun., 2011, 47, 1707.

38 E. L. Spitler, B. T. Koo, J. L. Novotney, J. W. Colson, F. J. UribeRomo, G. D. Gutierrez, P. Clancy and W. R. Dichtel, J. Am. Chem. Soc., 2011, 133, 19416. 
39 S. Wan, J. Guo, J. Kim, H. Ihee and D. L. Jiang, Angew. Chem. Int. $E d ., 2008,47,8826$.

40 S. Wan, J. Guo, J. Kim, H. Thee and D. L. Jiang, Angew. Chem. Int. $E d ., 2009,48,5439$.

41 Y. J. Choi, J. H. Choi, K. M. Choi and J. K. Kang, J. Mater. Chem., 2011, 21, 1073.

42 P. Kuhn, M. Antonietti and A. Thomas, Angew. Chem. Int. Ed., 2008, 47, 3450 .

43 M. J. Bojdys, J. Jeromenok, A. Thomas and M. Antonietti, Adv. Mater., 2010, 22, 2202.

44 S. J. Ren, M. J. Bojdys, R. Dawson, A. Laybourn, Y. Z. Khimyak, D. J. Adams, and A. I. Cooper, Adv. Mater., 2012, 24, 2357.

45 R. Palkovits, M. Antonietti, P. Kuhn, A. Thomas and F. Schüth, Angew. Chem. Int. Ed., 2009, 48, 6909.

46 C. E. Chan-Thaw, A. Villa, L. Prati and A. Thomas, Chem. Eur. J., 2011, 17, 1052.

47 P. Kuhn, A. Thomas and M. Antonietti, Macromolecules, 2009, 42, 319.

48 C. E. Chan-Thaw, A. Villa, P. Katekomol, D. S. Su, A. Thomas and L. Prati, Nano Lett., 2010, 10, 537.

49 P. Kuhn, A. Forget, D. S. Su, A. Thomas and M. Antonietti, J. Am. Chem. Soc., 2008, 130, 13333.

50 S. Hug, M. E. Tauchert, S. Li, U. E. Pachmayr and B. V. Lotsch, J. Mater. Chem., 2012, 22, 13956.

51 H. Y. Zhao, Z. Jin, H. M. Su, X. F. Jing, F. X. Sun and G. S. Zhu, Chem. Commun., 2011, 47, 6389.

52 F. J. Uribe-Romo, C. J. Doonan, H. Furukawa, K. Oisaki and O. M. Yaghi, J. Am. Chem. Soc., 2011, 133, 11478.

53 Z. H. Xiang, D. P. Cao, W. C. Wang, W. T. Yang, B. Y. Han and J. M. Lu, J. Phys. Chem. C, 2012, 116, 5974.

54 J. X. Jiang, F. B. Su, A. Trewin, C. D. Wood, H. J. Niu, J. T. A. Jones, Y. Z. Khimyak and A. I. Cooper, J. Am. Chem. Soc., 2008, 130, 7710 .

55 T. Ben, K. Shi, Y. Cui, C. Y. Pei, Y. Zuo, H. Guo, D. L. Zhang, J. Xu, F. Deng, Z. Q. Tian and S. L. Qiu, J. Mater. Chem., 2011, 21, 18208.

56 I. Berlanga, R. Mas-Ballesté and F. Zamora, Chem. Commun., 2012, 48, 7976.

57 R. Dawson, D. J. Adams and A. I. Cooper, Chem. Sci., 2011, 2, 1173.

58 H. Ren, T. Ben, F. X. Sun, M. Y. Guo, X. F. Jing, H. P. Ma, K. Cai, S. L. Qiu and G. S. Zhu, J. Mater. Chem., 2011, 21, 10348.

59 K. T. Jackson, T. E. Reich and H. M. El-Kaderi, Chem. Commun., $2012,48,8823$.

60 E. L. Spitler and W. R. Dichtel, Nat. Chem., 2010, $2,672$.

61 E. L. Spitler, M. R. Giovino, S. L. White and W. R. Dichtel, Chem. Sci., 2011, 2, 1588.

62 S. Wan, F. Gándara, A. Asano, H. Furukawa, A. Saeki, S. K. Dey, L. Liao, M. W. Ambrogio, Y. Y. Botros, X. F. Duan, S. Seki, J. F. Stoddart and O. M. Yaghi, Chem. Mater., 2011, 23, 4094.

63 L. Chen, Y. Yang and D. L. Jiang, J. Am. Chem. Soc., 2010, 132, 9138.

64 A. Modak, M. Nandi, J. Mondal and A. Bhaumik, Chem. Commun., 2012, 48, 248.

65 M. G. Schwab, B. Fassbender, H. W. Spiess, A. Thomas, X. L. Feng and K. Müllen, J. Am. Chem. Soc., 2009, 131, 7216.

66 J. X. Jiang, F. B. Su, A. Trewin, C. D. Wood, N. L. Campbell, H. J. Niu, C. Dickinson, A. Y. Ganin, M. J. Rosseinsky, Y. Z. Khimyak and A. I. Cooper, Angew. Chem. Int. Ed., 2007, 46, 8574.

67 P. Pandey, A. P. Katsoulidis, I. Eryazici, Y. Y. Wu, M. G. Kanatzidis and S. T. Nguyen, Chem. Mater., 2010, 22, 4974.

68 R. Dawson, A. Laybourn, R. Clowes, Y. Z. Khimyak, D. J. Adams and A. I. Cooper, Macromolecules, 2009, 42, 8809.

69 L. Chen, Y. Honsho, S. Seki and D. L. Jiang, J. Am. Chem. Soc., 2010, 132, 6742.

70 J. X. Jiang, F. B. Su, H. J. Niu, C. D. Wood, N. L. Campbell, Y. Z. Khimyak and A. I. Cooper, Chem. Commun., 2008, 486.

71 X. Du, Y. L. Sun, B. Tan, Q. F. Teng, X. J. Yao, C. Y. Su and W. Wang, Chem. Commun., 2010, 46, 970.

72 M. K. Bhunia, S. K. Das, P. Pachfule, R. Banerjee and A. Bhaumik, Dalton Trans., 2012, 41, 1304.

73 S. Y. Ding, J. Gao, Q. Wang, Y. Zhang, W. G. Song, C. Y. Su and W. Wang, J. Am. Chem. Soc., 2011, 133, 19816.
74 H. M. El-Kaderi, J. R. Hunt, J. L. Mendoza-Cortés, A. P. Côté, R. E. Taylor, M. O'Keeffe and O. M. Yaghi, Science, 2007, 316, 268.

75 Y. Yuan, H. Ren, F. X. Sun, X. F. Jing, K. Cai, X. J. Zhao, Y. Wang, Y. Wei and G. S. Zhu, J. Mater. Chem., 2012, 22, 24558.

76 Y. Yuan, H. Ren, F. X. Sun, X. F. Jing, K. Cai, X. J. Zhao, Y. Wang, Y. Wei and G. S. Zhu, J. Phys. Chem. C, 2013, DOI: 10.1021/jp309068x.

77 J. R. Hunt, C. J. Doonan, J. D. LeVangie, A. P. Côté and O. M. Yaghi, J. Am. Chem. Soc., 2008, 130, 11872.

78 E. Klontzas, E. Tylianakis and G. E. Froudakis, Nano Lett., 2010, 10, 452.

79 H. Ren, T. Ben, E. S. Wang, X. F. Jing, M. Xue, B. B. Liu, Y. Cui, S. L. Qiu and G. S. Zhu, Chem. Commun., 2010, 46, 291.

80 W. Wang, H. Ren, F. X. Sun, K. Cai, H. P. Ma, J. S. Du, H. J. Zhao and G. S. Zhu, Dalton Trans., 2012, 41, 3933.

81 H. P. Ma, H. Ren, X. Q. Zou, F. X. Sun, Z. J. Yan, K. Cai, D. Y. Wang and G. S. Zhu, J. Mater. Chem. A, 2013, DOI: 10.1039/c2ta00616b.

82 L. Zhao and C. L. Zhong, J. Phys. Chem. C, 2009, 113, 16860.

83 B. Assfour and G. Seifert, Chem. Phys. Lett., 2010, 489, 86.

84 Y. J. Choi, J. W. Lee, J. H. Choi and J. K. Kang, Appl. Phys. Lett., 2008, 92, 173102.

85 D. P. Cao, J. H. Lan, W. C. Wang and B. Smit, Angew. Chem. Int. Ed., 2009, 48, 4730.

86 T. Ben, H. Ren, S. Q. Ma, D. P. Cao, J. H. Lan, X. F. Jing, W. C. Wang, J. Xu, F. Deng, J. M. Simmons, S. L. Qiu and G. S. Zhu, Angew. Chem. Int. Ed., 2009, 48, 9457.

87 Y. Yuan, F. X. Sun, H. Ren, X. F. Jing, W. Wang, H. P. Ma, H. J. Zhao and G. S. Zhu, J. Mater. Chem., 2011, 21, 13498.

88 J. H. Lan, D. P. Cao, W. C. Wang, T. Ben and G. S. Zhu, J. Phys. Chem. Lett., 2010, 1, 978.

89 F. J. Uribe-Romo, J. R. Hunt, H. Furukawa, C. Klöck, M. O’Keeffe and O. M. Yaghi, J. Am. Chem. Soc., 2009, 131, 4570.

90 D. S. Zhang, Z. Chang, Y. B. Lv, T. L. Hu and X. H. Bu, RSC Adv., 2012, 2, 408.

91 T. Ben, C. Y. Pei, D. L. Zhang, J. Xu, F. Deng, X. F. Jing and S. L. Qiu, Energy Environ. Sci., 2011, 4, 3991.

92 K. Konstas, J. W. Taylor, A. W. Thornton, C. M. Doherty, W. X. Lim, T. J. Bastow, D. F. Kennedy, C. D. Wood, B. J. Cox, J. M. Hill, A. J. Hill and M. R. Hill, Angew. Chem. Int. Ed., 2012, 51, 6639.

93 W. G. Lu, J. P. Sculley, D. Q. Yuan, R. Krishna, Z. W. Wei and H. C. Zhou, Angew. Chem. Int. Ed., 2012, 51, 7480.

94 A. Comotti, S. Bracco, M. Mauri, S. Mottadelli, T. Ben, S. L. Qiu and P. Sozzani, Angew. Chem. Int. Ed., 2012, 51, 10136.

95 Y. X. Sun, T. Ben, L. Wang, S. L. Qiu and H. Sun, J. Phys. Chem. Lett., 2010, 1, 2753.

96 W. Chaikittisilp, A. Sugawara, A. Shimojima and T. Okubo, Chem. Mater., 2010, 22, 4841.

97 M. F. Roll, J. W. Kampf, Y. Kim, E. Yi and R. M. Laine, J. Am. Chem. Soc., 2010, 132, 10171.

98 Y. Peng, T. Ben, J. Xu, M. Xue, X. F. Jing, F. Deng, S. L. Qiu and G. S. Zhu, Dalton Trans., 2011, 40, 2720.

99 X. F. Jing, F. X. Sun, H. Ren, Y. Y. Tian, M. Y. Guo, L. N. Li, G. S. Zhu, Microporous Mesoporous Mater., 2013, 165, 92.

100 H. J. Jeon, J. H. Choi, Y. Lee, K. M. Choi, J. H. Park and J. K. Kang, Adv. Energy Mater., 2012, 2, 225.

101 M. H. Weston, O. K. Farha, B. G. Hauser, J. T. Hupp and S. T. Nguyen, Chem. Mater., 2012, 24, 1292.

102 K. V. Rao, R. Haldar, C. Kulkarni, T. K. Maji and S. J. George, Chem. Mater., 2012, 24, 969.

103 J. L. Mendoza-Cortes, W. A. Goddard, H. Furukawa and O. M. Yaghi, J. Phys. Chem. Lett., 2012, 3, 2671.

104 S. S. Han, H. Furukawa, O. M. Yaghi and W. A. Goddard, J. Am. Chem. Soc., 2008, 130, 11580.

105 Q. Chen, J. X. Wang, F. Yang, D. Zhou, N. Bian, X. J. Zhang, C. G. Yan and B. H. Han, J. Mater. Chem., 2011, 21, 13554.

106 U. Stoeck, G. Nickerl, U. Burkhardt, I. Senkovska and S. Kaskel, J. Am. Chem. Soc., 2012, 134, 17335.

107 J. R. Holst and A. I. Cooper, Adv. Mater., 2010, 22, 5212.

108 J. R. Holst, E. Stöckel, D. J. Adams and A. I. Cooper, Macromolecules, 2010, 43, 8531. 
109 D. Q. Yuan, W. G. Lu, D. Zhao and H. C. Zhou, Adv. Mater., 2011, 23, 3723.

Xiaoqin Zou received his Bachelor (2006) and Master degrees (2009) in Materials Chemistry from Jilin University in China. He then was awarded a scholarship from 2009 to 2012 by the China Scholarship Council (CSC) to pursue his $\mathrm{PhD}$ study in the Laboratory of Catalysis and Spectroscopy (University of Caen, France), under the supervision of Dr. Svetlana Mintova with a focus on the development of zeolitic materials as membranes. His current scientific interests include the synthesis, characterization and advanced applications of novel nanoporous materials.

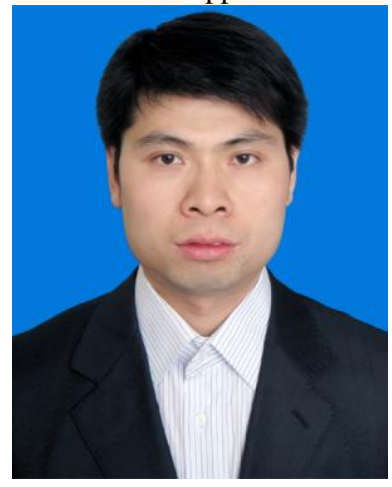

Hao Ren obtained his Bachelor degree in Chemistry from Jilin University in 2006. Then, he joined the research group of Professor Guangshan Zhu for his further Master and $\mathrm{PhD}$ studies, mainly working on targeted synthesis of porous aromatic frameworks for gas storage. After receiving his $\mathrm{PhD}$ degree in 2011, he began his academic career as an assistant professor at the Department of Chemistry, Jilin University. His scientific research interests are focused on the synthesis, structure and functions of porous organic frameworks.

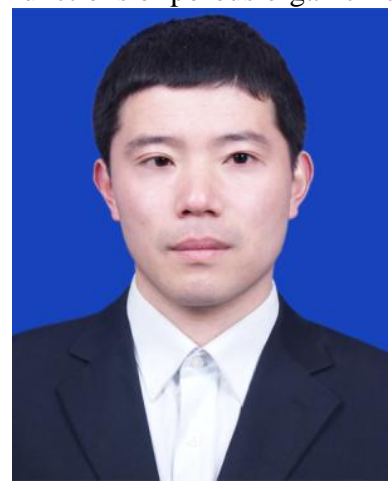

Guangshan Zhu studied Chemistry in 1993 and earned his PhD in Chemistry from Jilin University (China) in 1998. He then was immediately appointed as an assistant professor at the Department of Chemistry (Jilin University). In 1999, he worked as a post-doc research associate at Tohoku University in Japan. He has been a full professor since 2001; and now holds Cheung Kong Professorship from the Ministry of Education of China, and Visiting Professorship in Griffith University (Australia). The current research in his group focuses on the design and synthesis of zeolite, metal organic frameworks and porous organic frameworks for the applications in gas/liquid adsorption, separation, and other advanced applications.

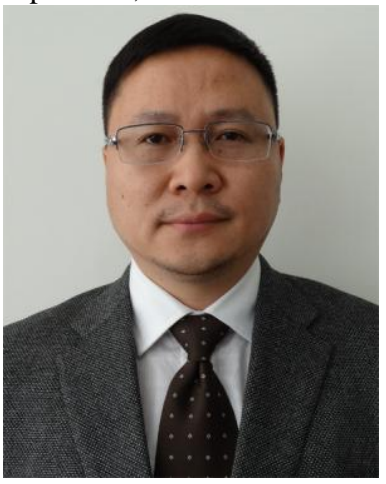

